\title{
In vitro evaluation of anti-proliferative, anti-inflammatory and pro-apoptotic activities of the methanolic extracts of Andrographis nallamalayana Ellis on A375 and B16F10 melanoma cell lines
}

\author{
Guroji Purushotham $^{1,2} \cdot$ Yerukala Padma $^{1}$-Yusuf Nabiha ${ }^{2}$ R. R. Venkata Raju'
}

Received: 10 May 2016/Accepted: 19 September 2016/Published online: 1 October 2016

(C) The Author(s) 2016. This article is published with open access at Springerlink.com

\begin{abstract}
Natural plant products have been widely used in controlling cancer with fewer or no side effects and the use of plant extracts as complementary to synthetic medicine is gaining increased popularity. Members of Andrographis plants possess important medicinal properties. In the present study, anti-cancerous properties of Andrographis nallamalayana (AN) were tested on A375 and B16F10 skin melanoma cancer cell lines. The leaf extracts of AN significantly reduced the cell viability and cell survival of skin cancer cell lines, achieved by MTT assay and clonogenic assays, respectively. Further, TUNEL assays revealed that AN extracts induces the apoptosis. Western blot analysis revealed that AN leaf extracts reduced the expression of $\mathrm{Bcl}-2$, an anti-apoptotic protein and induced the expression of proapoptotic molecules such as Bcl-2 associated death promoter protein (BAD), $\mathrm{Bcl}-2$ associated $\mathrm{X}$ protein $(\mathrm{BAX})$ and cleaved caspase-3. Moreover, the qRT-PCR and western blot analysis demonstrated the reduced expression of G2/ $M$ phase proteins cdk1, cyclin B1 and increased expression of p53, cyclin-dependent kinase 1 inhibitor, p21. Further, immunofluorescence analysis revealed that AN reduced the NF- $\kappa \mathrm{B}$ nuclear translocation, luciferase reporter assays demonstrated reporter gene activation. qRT-PCR assays showed that AN significantly reduced
\end{abstract}

R. R. Venkata Raju

rrvenkataraju@yahoo.com

1 Phytomedicine Division, Department of Botany, Sri Krishnadevaraya University, Anantapuram, Andhra Pradesh 515003, India

2 Department of Dermatology and Skin Diseases Research Center, University of Alabama at Birmingham (UAB), Birmingham, AL 35294, USA the expression of NF- $\kappa \mathrm{B}$ target genes. The results concluded that the extracts of AN exhibited significant antiproliferative, anti-inflammatory and pro-apoptotic activities on melanoma skin cancer cell lines.

Keywords Andrographis nallamalayana (AN) . Cancer - Skin cancer - Cell cycle arrest - Apoptosis

\section{Introduction}

Medicinal plants were being used to treat various chronic diseases from ancient times. Natural plant products have shown their potentiality in controlling cancer while exhibiting less or no side effects and the use of plant extracts as complimentary to modern medicine is gaining increased popularity. Up to $80 \%$ population in the developing countries is depending on herbal medicine to heal different diseases and they are inaccessible to allopathic medicine (Ekor 2014; Pandey et al. 2013; Mzid et al. 2012; Rates 2001). Some species of Andrographis gained its own importance due to their important medicinal values and an effective anti-cancerous source (Agbonlahor et al. 2014; Dhiman et al. 2012; Abhishek et al. 2010). Members of Andrographis are widely used in various ailments; particularly, Andrographis paniculata Nees (A. paniculata) used in the treatments of wide varieties of diseases in traditional systems of the medicine (Agbonlahor et al. 2014). A. paniculata extracts were tested against variety of cancer cell lines and reported that compounds isolated from the extracts exhibited potent anti-tumor activity against all the investigated cancer cell lines (Luo et al. 2014; Lin et al. 2014; Geethangili et al. 2008; Rajagopal et al. 2003). It has also been showed that the methanol extract of A. paniculata was subjected to fractionation and reported that

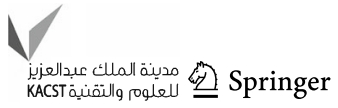


dichloromethane fraction of methanolic extract possessing cytotoxic activity and also potent immunostimulating activity (Sagadevan et al. 2015; Churiyah et al. 2015; Ajay et al. 2004). However, it was also reported that there were also adverse side effects of $A$. paniculata which may include gastric upset, headache, bitter taste and fatigue. Moreover, reports revealed that the high doses of $A$. paniculata may affect the normal functions of liver (Prakash et al. 2013). Hence, exploring more species of the Andrographis for medicinal properties including anticancer properties may prove to be worthwhile.

AN which was used in this study is procumbent herb, endemic to Nallamala hills, Andhra Pradesh, India. This herb was known to be used for treating mouth ulcers (Venkata Ratnam and Venkata Raju 2005) as well as leukoderma in folklore medicine and recent reports showed that parts of this herb were persisting antimicrobial and anti-psoriatic properties, respectively (Padma and Venkata Raju 2013; Parlapally et al. 2015). However, the anticancerous properties of $\mathrm{AN}$ are hitherto unknown. In the present study, we examined the anti-cancerous properties such as antiproliferative and pro-apoptotic effects of the methanolic extracts of AN on skin cancer cell lines, A375 and B16F10 and unraveled the detailed molecular mechanism of action of the test extracts.

\section{Materials and methods}

\section{Reagents}

A375 and B16F10 cell lines were obtained from American Type Culture Collection (ATCC). DMEM media, antibiotics penicillin and streptomycin were purchased from Gibco BRL (CA, USA). Fetal bovine serum (FBS) was purchased from Hyclone Laboratories Ltd (Logan, UT). TNF- $\alpha$, trypsin-EDTA, protease inhibitor cocktail were purchased from Sigma Chemicals (St Louis, MO, USA). All primary antibodies [BAX, p-BAD, BAD, B cell lymphoma-extralarge (Bcl-XL), p53, cyclin B1, Cell division cycle 25c (Cdc25c), p-cdc25c, caspase-3, and GAPDH] were purchased from Cell Signaling Technology (Beverly, MA, USA) and secondary antibodies from Sigma Chemicals (St Louis, MO, USA).

\section{Preparation of plant extract}

The well-developed matured plant parts of AN were collected from the forests of Nallamalais, central region of Eastern Ghats. The specimen was identified with the help of the regional floras and the voucher specimen was deposited at Sri Krishnadevaraya University Herbarium (SKU), Ananthapuramu. The collected plant parts were washed with tap water, shade dried, powdered and extracted with petroleum ether, ethyl acetate and methanol using Soxhlet apparatus for $6 \mathrm{~h}$. The extracts were filtered through Whatman number 1 filter paper and the filtrates were concentrated under reduced pressure at $40{ }^{\circ} \mathrm{C}$ using a rotoflash evaporator. Dried powder was dissolved in dimethyl sulfoxide (DMSO) for treatments.

\section{Cell culture}

A375 and B16F10 cell lines were cultured in DMEM media supplemented with $10 \% \mathrm{FBS}, 100 \mathrm{IU} / \mathrm{ml}$ penicillin and $100 \mu \mathrm{g} / \mathrm{ml}$ of streptomycin in a humidified atmosphere with $5 \% \mathrm{CO}_{2}$ at $37{ }^{\circ} \mathrm{C}$. Cell lines were passaged in the laboratory for less than 6 months.

\section{MTT cell viability assays}

The effects of the extracts of AN on cell proliferation of A375 and B16F10 cell lines were performed using MTT cell viability assays. Inhibition of cell proliferation was measured by the reduction of 3-(4,5-dimethylthiazol-2-yl)-2,5-diphenyltetrazolium bromide (MTT) to formazan. A375 and B16F10 cells were seeded (2000 cells/well) in 96 wells plates, after overnight incubation cells were treated with varying concentrations of methanolic extracts of leaf and stem of AN for $72 \mathrm{~h}$ $(10,50,100$ and $150,200,250$ and $300 \mu \mathrm{g})$ or vehicle $(0.1 \%$ DMSO). Then MTT reagent was added to the medium in each well and incubated for $4 \mathrm{~h}$ at $37{ }^{\circ} \mathrm{C}$. Then, reduced formazan crystals were solubilized in DMSO was then the optical density values were measured at $540 \mathrm{~nm}$ on micro plate reader. All treatments were performed in triplicate and results were expressed as mean $\pm \mathrm{SE}$.

\section{Clonogenic assays}

Effect of AN on colony formation ability of A375 and B16 F10 cells was performed using clonogenic survival assays. A375 and B16F10 cells plated at a density of 500 cells/well in six well plates. After overnight incubation cells were treated with AN leaf extracts or vehicle (0.1\% DMSO) for $48 \mathrm{~h}$. Then cells were allowed to grow for additional 7 days and colonies were stained with $0.5 \%$ methylene blue in $50 \%$ methanol. Colonies that contain more than 50 cells were counted. All treatments were performed in triplicate and results expressed as mean $\pm \mathrm{SE}$.

\section{Terminal deoxynucleotidyl transferase dUTP nick end labeling (TUNEL) assay}

An in situ apoptosis detection kit was used to detect DNA fragmentation in accordance with the manufacturer's procedure (Roche, Indianapolis, IN, USA). Briefly, B16F10 
and A375 cells were grown on chamber slides, treated with AN for $48 \mathrm{~h}$. The cells were then fixed with $4 \%$ paraformaldehyde for $10 \mathrm{~min}$, and then incubated for 60 min with a reaction mixture containing fluorescein conjugated-dUTP and terminal deoxynucleotidyl transferase. Positively stained fluorescein-labeled cells were visualized and photographed using a fluorescence microscope. DAPI was used to visualize the nuclei.

\section{Western blotting}

$50 \mu \mathrm{g}$ of total cellular lysates was mixed with SDS sample buffer, boiled for $5 \mathrm{~min}$ and subjected to electrophoresis on 10 and $12 \%$ SDS-polyacrylamide gels. Then resolved proteins were transferred onto PVDF membranes for overnight at $4{ }^{\circ} \mathrm{C}$. Membranes were incubated in blocking buffer [5\% non-fat dry milk in tris buffered saline (TBS) (10 mM Tris ( $\mathrm{pH} 7.5$ ), $150 \mathrm{mM} \mathrm{NaCl}$ ] for $2 \mathrm{~h}$, and then incubated with the primary antibodies in blocking buffer for overnight at $4{ }^{\circ} \mathrm{C}$. The membranes were then washed with TBS-T (TBS contacting $0.1 \%$ Tween-20) thrice for 10 min each and incubated with secondary antibody conjugated with horseradish peroxidase for $2 \mathrm{~h}$ at room temperature. Protein bands were visualized using the enhanced chemiluminescence detection system.

\section{RNA isolation}

Total RNA was extracted from A375 cells that are treated with methanolic leaf extracts of $\mathrm{AN}$ or vehicle $(0.1 \%$ DMSO) for $24 \mathrm{~h}$ using Trizol Reagent (Invitrogen, Carlsbad, CA, USA) according to manufacturer's protocol. RNA samples were properly dissolved by incubating at $55^{\circ} \mathrm{C}$ for $10 \mathrm{~min}$. DNA contamination was removed by treatment with DNase I (Invitrogen \#18047019) for $30 \mathrm{~min}$ at $37{ }^{\circ} \mathrm{C}$ followed by heat inactivation of DNase I prior to quantification using Nano-Drop spectrophotometer. The purified RNA was stored at $-80{ }^{\circ} \mathrm{C}$ until further use.

\section{cDNA synthesis and real-time qRT-PCR}

First strand cDNA synthesis was done using iScript ${ }^{\mathrm{TM}} \mathrm{cDNA}^{\mathrm{C}}$ synthesis kit (Biorad \#170-8897) by following manufacturer's protocols. The cDNA obtained was used to perform real-time qRT-PCR in a Bio-Rad iCycler iQ5TM Real-Time PCR detection system using $2 \mathrm{X}$ iQ SYBR Super mix (Invitrogen \#K0242). The sequences of primers (from $5^{\prime}$ end to $3^{\prime}$ end) used for qRT-PCR are followed. CyclinD1-F' ${ }^{\prime}$ TCCAGAGT GATCAAGTGTGA-3', CyclinD1-R-GATGTCCACGTCC CGCACGT, CDK1-F-CCTTGCCAGAGCTTTTGGAATA CC-3',CDK1-R-GACATGGGATGCTAGGCTTCCTGG, cyclinB-F-TGGAAAAGTTGGCTCCAAAG, cyclin B-RTCAGAAAAAGCTTGGCAGAGA, Actin-F-GTGGGCA
TGGGTCAGAAG, Actin-R-TCCATCACGATGCCAG TG. The gene expression levels were determined using the cycle threshold $\left(C_{\mathrm{t}}\right)$ method. The mean $C_{\mathrm{t}}$ values from duplicate measurements were used to calculate the expression of the target gene with normalization to a housekeeping gene and the difference in fold expression was calculated using $\Delta \Delta C_{\mathrm{t}}$ method.

\section{Transient transfection and luciferase assays}

To examine the effect of leaf extracts of $\mathrm{AN}$ on $\mathrm{NF}-\kappa \mathrm{B}$ reporter gene activation, $\mathrm{B} 16 \mathrm{~F} 10$ melanoma cells were seeded in triplicates in 24-well plates $(25,000$ cells/well). After overnight incubation, cells were transiently transfected with $0.5 \mu \mathrm{g}$ of pNFkB-Luc-Reporter, and $0.1 \mu \mathrm{g}$ of pRL-TK (for normalization of transfection efficiency) vectors using fugene 6 transfection reagent. After 6 h, fresh medium was added to cells. $24 \mathrm{~h}$ after transfection, cells were treated with different concentrations of methanolic leaf extracts of AN for $48 \mathrm{~h}$ followed by TNF- $\alpha(10 \mathrm{ng} / \mathrm{ml})$ treatment. The cell culture medium was harvested after $24 \mathrm{~h}$ and luciferase activity was measured using dual luciferase assay system according to the manufacturers protocol (Clontech, USA). For renilla luciferase activities, cells were lysed in passive lysis buffer and measured the luciferase activities with luminometer (Promega, Madison, WI, USA). NF- $\kappa$ B-luciferase activities were normalized with that of renilla luciferase values.

\section{Immunofluorescence}

To examine the effect of $\mathrm{AN}$ on p65, B16F10 cells were seeded in chamber plates and after overnight incubation cells were treated with methanolic leaf extracts of AN for $48 \mathrm{~h}$. Cells were then stimulated with $\mathrm{TNF} \alpha(10 \mathrm{ng} / \mathrm{ml})$ for $30 \mathrm{~min}$, and fixed with $4 \%$ paraformaldehyde for $10 \mathrm{~min}$ at room temperature followed by permeabilization with $0.2 \%$ Triton X-100. After blocking with $5 \%$ goat serum for $1 \mathrm{~h}$, cells were incubated with p65 primary antibody for overnight at $4{ }^{\circ} \mathrm{C}$. After three washes with phosphate buffered saline (PBS), cells were incubated with anti-FITC conjugated rabbit secondary antibody for $1 \mathrm{~h}$ at room temperature. Cells were washed thrice with PBS and cover slips were mounted with VECTA SHIELD mounting medium and fluorescence was captured under fluorescence microscope. The DNA dye 4',6-diamidino-2-phenylindole (DAPI) was used to visualize the nucleus.

\section{Statistical analysis}

All data were expressed as mean \pm standard error (SE) obtained from at least three independent experiments. SPSS software for Windows, version 20 (SPSS, Chicago, 
IL, USA) was used for statistical analysis. Statistical comparisons among two groups were carried out by student's $t$ test. Differences were considered to be statistically significant at a $P$ value of $<0.05$.

\section{Results}

\section{Antiproliferative effects of AN on skin cancer cell lines}

Previous reports suggest that A. paniculata exhibited antiproliferative effect on various cancer cell lines; however, much is not known about the other species including AN. To know whether AN possesses antiproliferative properties on cancer cell lines, first methanolic extracts of stem and leaf of the test plants were prepared. Then, the extracts were used to test their effect on cell viability using MTT assays. Human skin cancer cell line A375, and mouse skin cancer cell line $\mathrm{B} 16 \mathrm{~F} 10$ were treated with various concentrations of AN for $72 \mathrm{~h}$. Results showed that methanolic extracts of stem and leaf of AN significantly reduced the cell viability of A375 and B16F10 (Fig. 1) cancer cell lines in dose-dependent manner. When compared to stem extracts, leaf extracts were highly efficient in reducing the cell viability of cancer cell lines. Next, cellular morphology of A375 and B16F10 cells upon leaf extracts treatment were examined. Cell lines were treated with 100 and $200 \mu \mathrm{g}$ of AN leaf extracts for $72 \mathrm{~h}$ and images were captured under bright filed microscope. As shown in Fig. 2, AN extracts reduced the cell number and cells become round and displayed the apoptotic like features.

B16F10

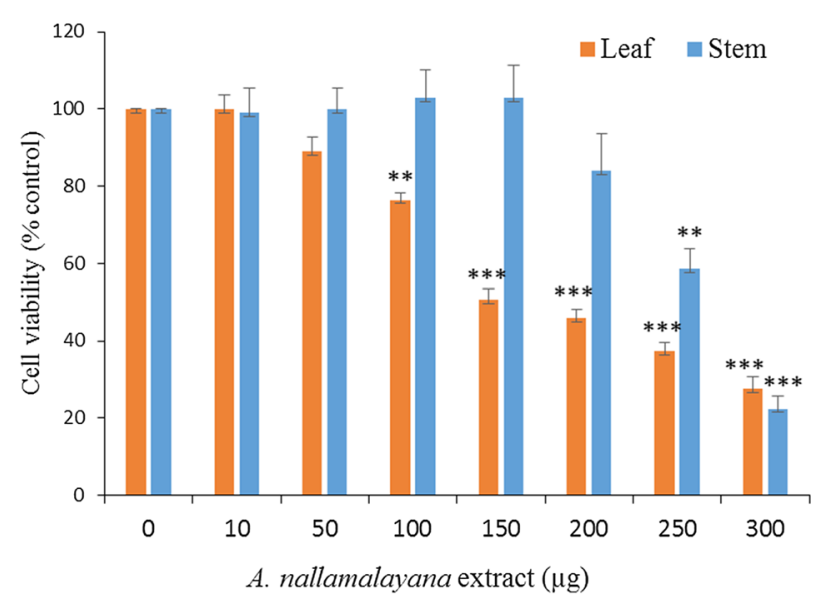

Fig. 1 Effect of A. nallamalayana on proliferation of A375 and B16F10 melanoma cells. B16F10 cancer cells were seeded in 96 well plates and treated with vehicle $(0.1 \%$ DMSO) or indicated concentrations of methanolic extracts from leaf and stem of $A$.

\section{AN leaf extracts reduces the colony formation of A375 and B16F10 skin cancer cell lines}

In addition to reducing the cell viability, other important feature of chemotherapeutic drugs is reducing the survival of cancer cell lines. In the present study, the effect of AN extracts on cell survival was evaluated by employing clonogenic survival assays. Cells were treated with methanolic extracts for $72 \mathrm{~h}$ and allowed in growth medium to grow into colonies for 7 days. Cells treated with AN leaf extracts have not shown any colony formations whereas vehicle treated cells have shown well-developed colonies. Untreated A375 and B16F10 cells attain around $80 \%$ of cloning efficiency, whereas AN treatment significantly reduced the cloning efficiency of skin cancer cells (Fig. 3). These results demonstrated that AN reduces the survival of skin cancer cell lines.

\section{AN leaf extracts induce the apoptosis of A375 and $\mathrm{B} 16 \mathrm{~F} 10$ cell lines}

Treatment with AN resulted in rounding of the cells and exhibited apoptotic-like features. To further determine whether AN extracts induces apoptosis of skin cancer cells, the extent of DNA fragmentation was determined by terminal deoxynucleotidyl transferase-mediated dUTP nick end labeling (TUNEL) assay and the apoptotic cells were marked with higher fluorescein isothiocyanate (FITC) fluorescent intensity with green color under a microscope. To localize the nucleus, DAPI was used as counter stain. As shown in Fig. 4, AN treatment significantly induces the apoptosis of B16F10 and A375 cell lines, respectively.

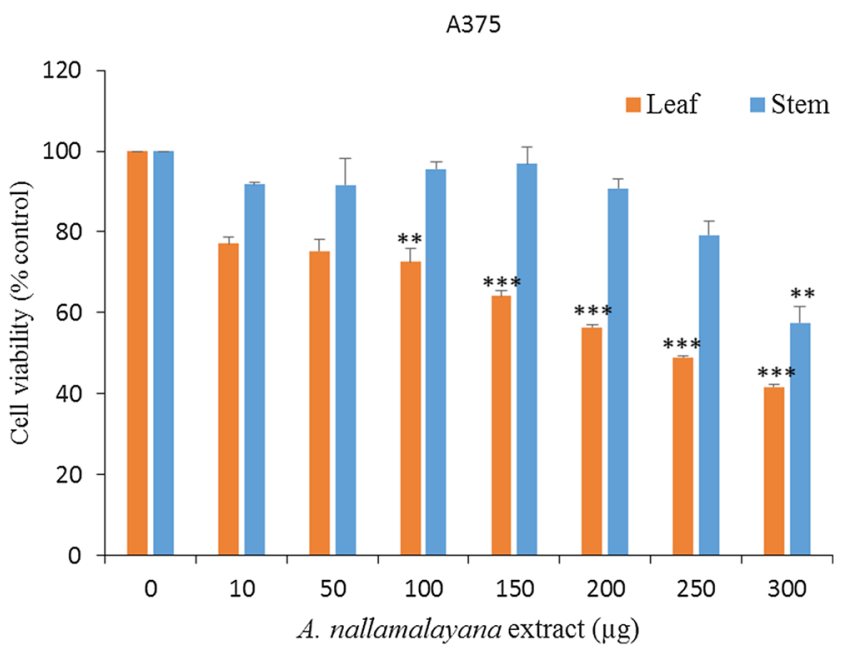

nallamalayana for $72 \mathrm{~h}$ and subjected to MTT assay. All data presented are the mean $\pm \mathrm{SE}$ and are representative of three independent experiments. ${ }^{* *} p<0.01,{ }^{* * *} p<0.001, t$ test. ' 0 ' denotes the vehicle-treated control cells 

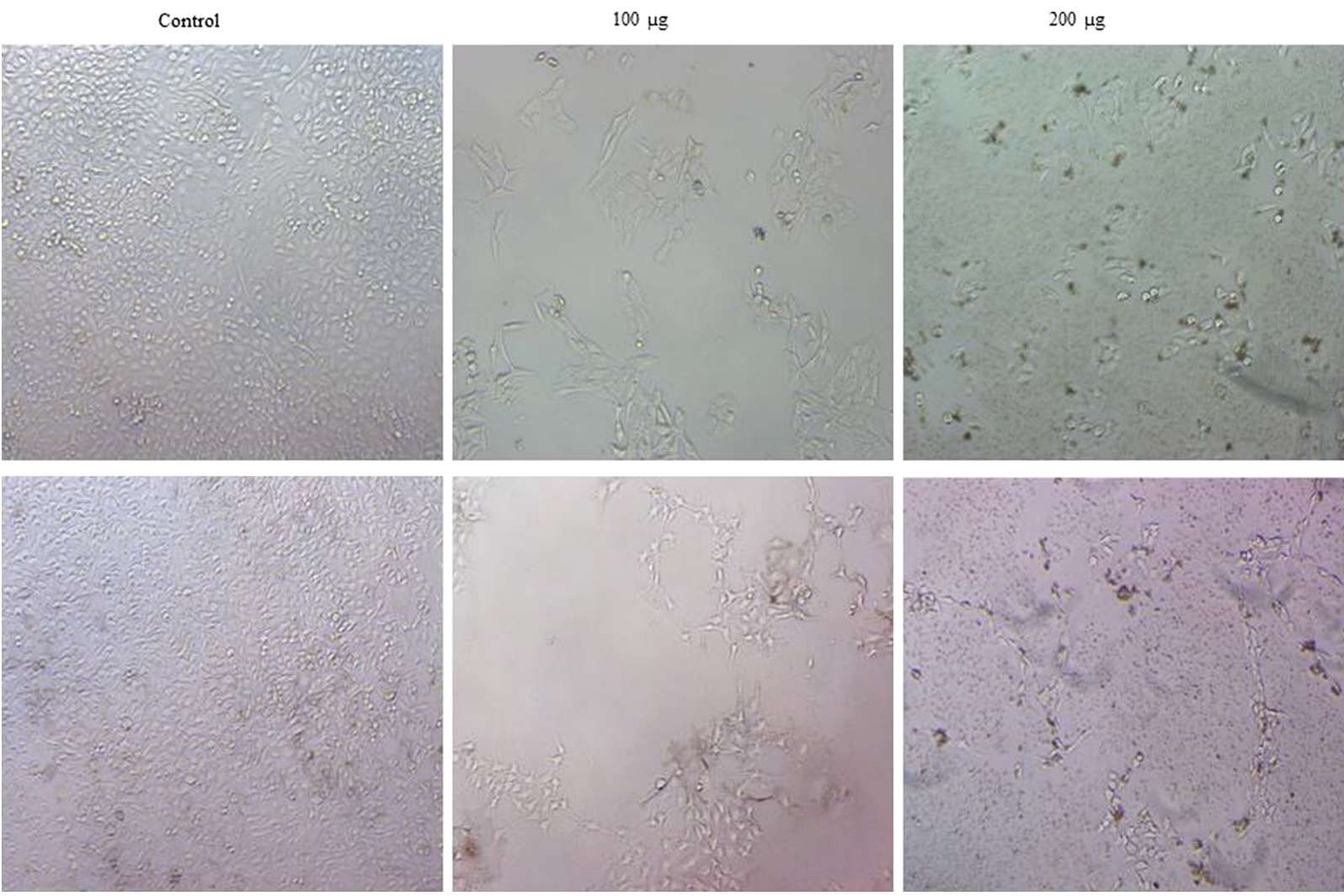

A 375
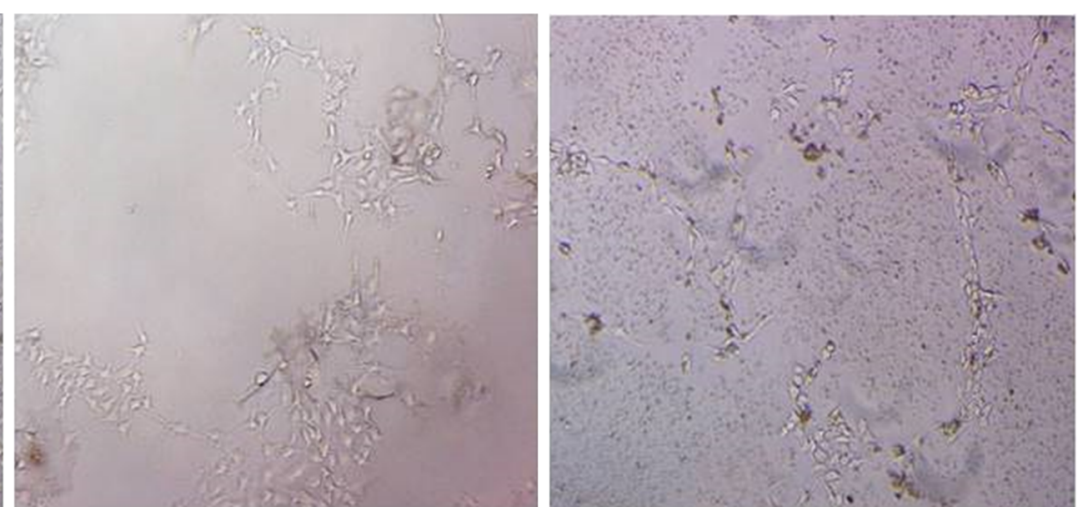

$\mathrm{B} 16 \mathrm{~F} 10$

Fig. 2 Effect of A. nallamalayana on cell number and morphology of A375 and B16F10 skin cancer cells. A375 and B16F10 cells were treated with vehicle $(0.1 \%$ DMSO) or indicated concentrations of

\section{AN leaf extracts alters the expression of proteins involved in G2/M phase transition}

To investigate the molecular mechanisms involved in the G2/M arrest A375 cell lines were treated with various doses of AN for $24 \mathrm{~h}$ and tested the expression and phosphorylation of several proteins that are involved in the G2/ $M$ transition using western blotting and qRT-PCR. After treating the cells with indicated concentrations of AN, the levels of cyclin B1 were analyzed by western blotting and real-time PCR. As shown in Fig. 5a, expression levels of cyclin B1 mRNA as well as protein (Fig. 5b) were downregulated in a concentration-dependent manner. However, the alterations in the expression of cyclins were not sufficient to explain the G2/M arrest induced by AN. G2/M progression depends not only upon the expression of $\mathrm{Cdk}$ inhibitors but also on phosphorylation of Cdk1 (Cdc2), the indicative of $\mathrm{Cdc} 2$ activity, which is negatively regulated by the phosphorylation of Thr14 and Tyr15. Cdc25c is a protein phosphatase that activates $\mathrm{Cdc} 2$ by dephosphorylation. Cdc25c is phosphorylated at ser216 in response to DNA damage at G2/M checkpoint and interacts with members of the 14-3-3 family of proteins, leading to its sequestration in the cytoplasm and thereby preventing methanolic leaf extracts of $A$. nallamalayana for $72 \mathrm{~h}$ and images were captured under bright filed microscope

premature mitosis. We next assessed the effect of AN on Cdc25c phosphorylation status. Western blot analysis revealed that AN treatment increased the levels of phosphorylated Cdc25c (Fig. 5b). We also examined the effects of $\mathrm{AN}$ on $\mathrm{Cdc} 25 \mathrm{c}$ protein expression, and observed that $\mathrm{Cdc} 25 \mathrm{c}$ was significantly downregulated in AN-treated A375 cells (Fig. 5b). The cyclin-dependent kinase 1 (Cdk1), formerly called Cdc2, interacts with cyclin B1 and forms $\mathrm{Cdk} 1 /$ cyclin $\mathrm{B} 1$ complex which regulates the progression from G2- to M phase. The effect of AN extracts on Cdk1 expression by qRT-PCR analysis was examined. As shown in Fig. 5a, AN treatment significantly reduces the expression of cdk1 dose dependently in A375 cells.

To further examine whether AN induces CDK inhibitor proteins, p21 protein levels were measured using western blot analysis up on AN extract treatments on A375 cells. AN treatment also induced a significant increase in p21 protein expression dose dependently (Fig. 5b). The expression of p21 is regulated by either a p53-dependent or p53-independent mechanism. In addition, p53 induces the cell cycle arrest as well apoptosis by regulating the expression of its target genes p21 and PUMA. To know whether the growth-inhibitory effect of AN was dependent on p53 status, p53 protein levels were tested following 

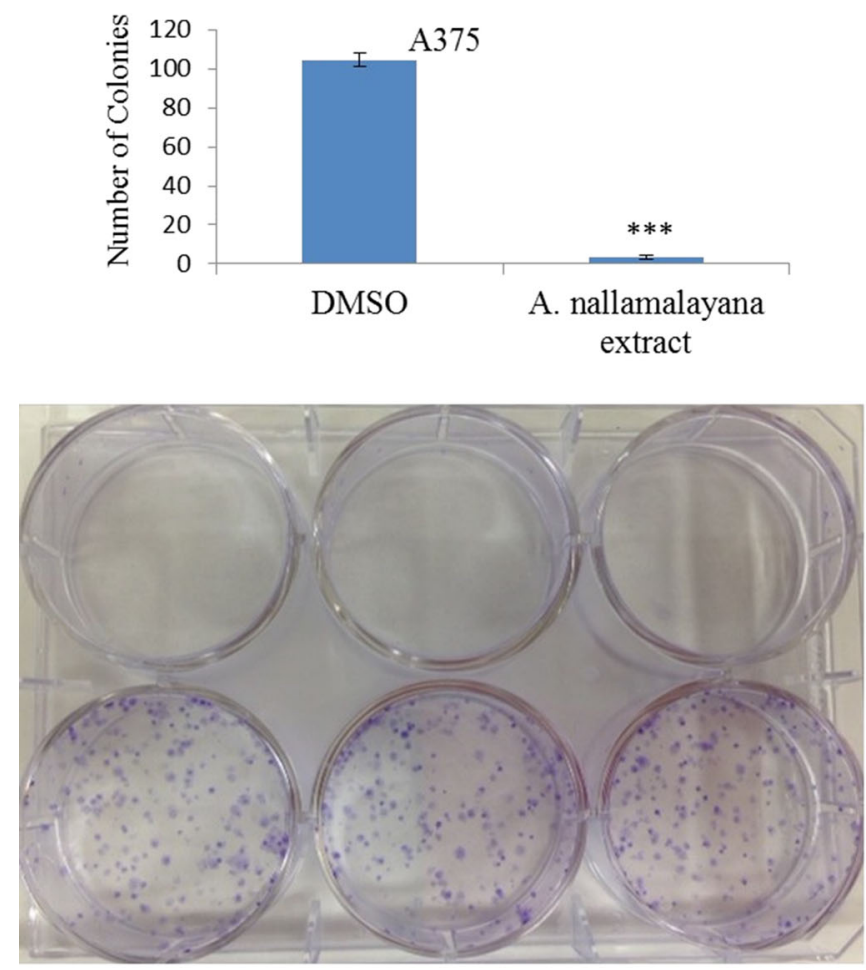

A. nallamalayana leaf extract on A375

Fig. 3 Effect of A. nallamalayana on colony formation of A375 and B16F10 cancer cells. $1 \times 10^{3}$ A 375 and B16F10 cells were plated in 6 well culture dishes in triplicates and after $24 \mathrm{~h}$ cells were treated with vehicle $(0.1 \%$ DMSO) or indicated concentrations of $A$.
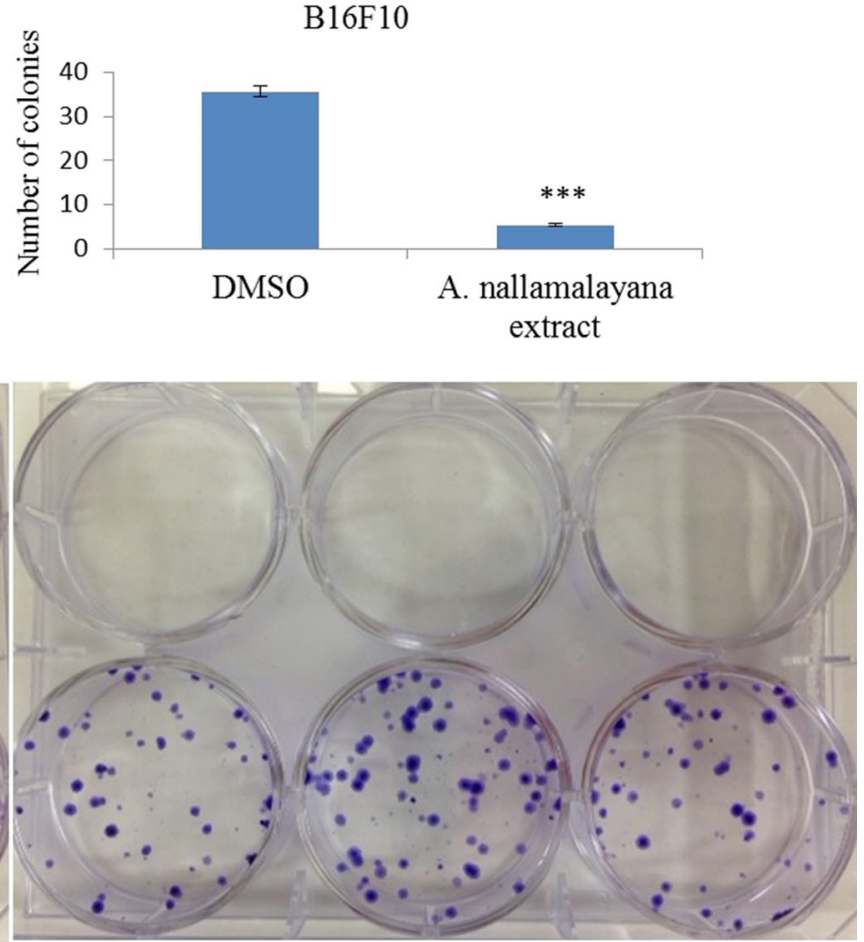

A. nallamalayana leaf extract on $\mathrm{B} 16 \mathrm{~F} 10$

nallamalayana for $48 \mathrm{~h}$. After 7 days colonies were stained with methylene blue and colonies that contain $\geq 50$ cells were counted. All data presented are the mean $\pm \mathrm{SE}$ and are representative of three independent experiments. ${ }^{* * *} p<0.001, t$ test

\section{$\mathrm{B} 16 \mathrm{~F} 10$}

Control

A. nallamalayana
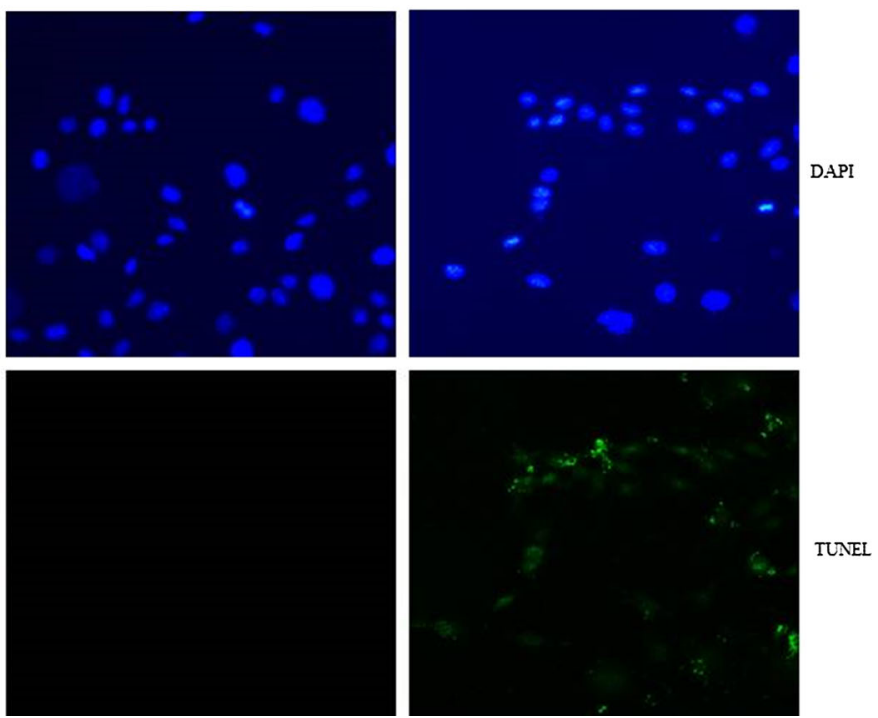

apoptosis assay according to manufacturer's protocol. DAPI was used to identify the nucleus and data are representative of three independent experiments
Fig. 4 Effect of A. nallamalayana on apoptosis of A375 and B16F10cancer cells. A375 and B16F10 cells were seeded in chamber plates and treated with vehicle $(0.1 \%$ DMSO) or $200 \mu \mathrm{g} \mathrm{A}$. nallamalayana for $72 \mathrm{~h}$. Then cells were subjected to TUNEL

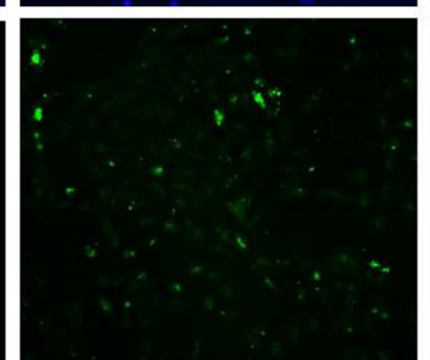




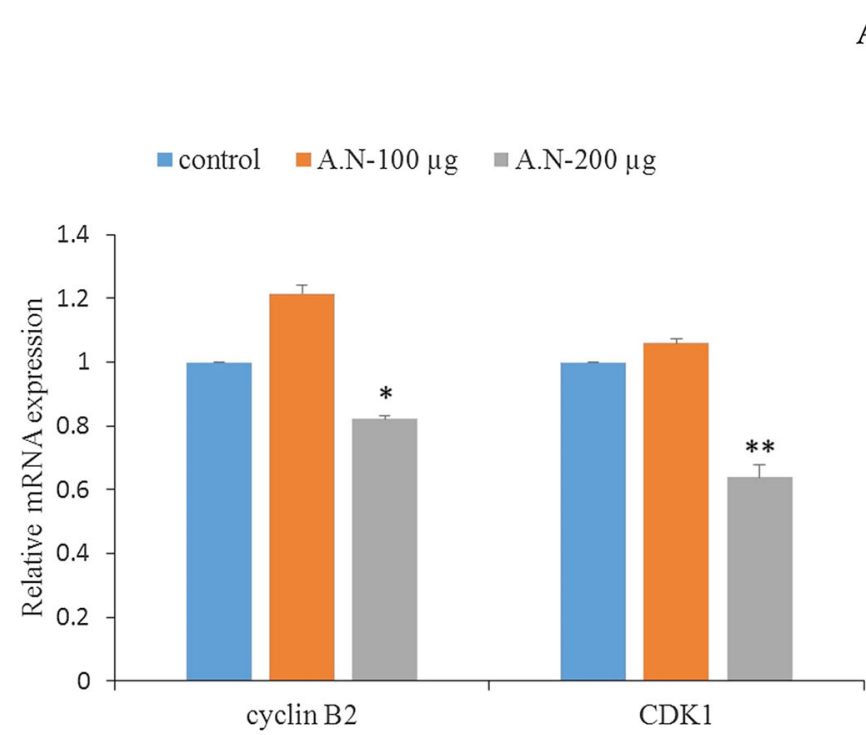

Fig. 5 a Effect of A. nallamalayana (A.N) on expression of cyclin B1 and cdk1 in A375 cancer cells. A375 cells were treated with vehicle $(0.1 \%$ DMSO) or indicated concentrations of A. nallamalayana for $24 \mathrm{~h}$. RNA was isolated and subjected to RT-qPCR using the primers specific for cyclin $\mathrm{B} 1$ and cdk1. All data presented are the mean \pm SE. $* p<0.05, * * p<0.01, t$ test. b Effect of $A$. nallamalayana (A.N) on protein levels of G2/M phase proteins. Cell lysates of A375 skin cancer cells treated with indicated concentrations of A. nallamalayana for $24 \mathrm{~h}$ and whole cell lysates were subjected to

treatment. As shown in Fig. 5b, the expression of p53 was significantly increased in A375 cells following AN treatment.

\section{AN leaf extracts enhances the expression of apoptotic proteins in A375 cells}

To better understand how AN extract induces apoptosis and reduced the cell survival of skin cancer cell lines; the expression of $\mathrm{Bcl}-2$ family proteins which involved in apoptosis and cell survival was analyzed. Pro-apoptotic proteins, including $\mathrm{BAD}$ and $\mathrm{BAX}$, can trigger the apoptotic cascade by forming pores in the mitochondrial membrane. The expression of pro-apoptotic molecules such as BAX, BAD and anti-apoptotic molecule Bcl-XL following AN treatment was measured. As shown in Fig. 5c, western blot analysis demonstrated that the expression of BAD, a pro-apoptotic BH3-only member of the Bcl-2 family was significantly increased in A375 cells following AN treatment compared to control cells (Fig. 5c). The levels of p-BAD was significantly reduced and $\mathrm{BAD}$ protein levels were significantly increased dose dependently following AN extract treatments in A375 cells. Further the protein levels of anti-apoptotic molecule Bcl-XL was examined following AN extract treatment. As shown in Fig. 5c, western blot analysis showed the significant down-regulation of Bcl-XL levels in AN-treated
A375
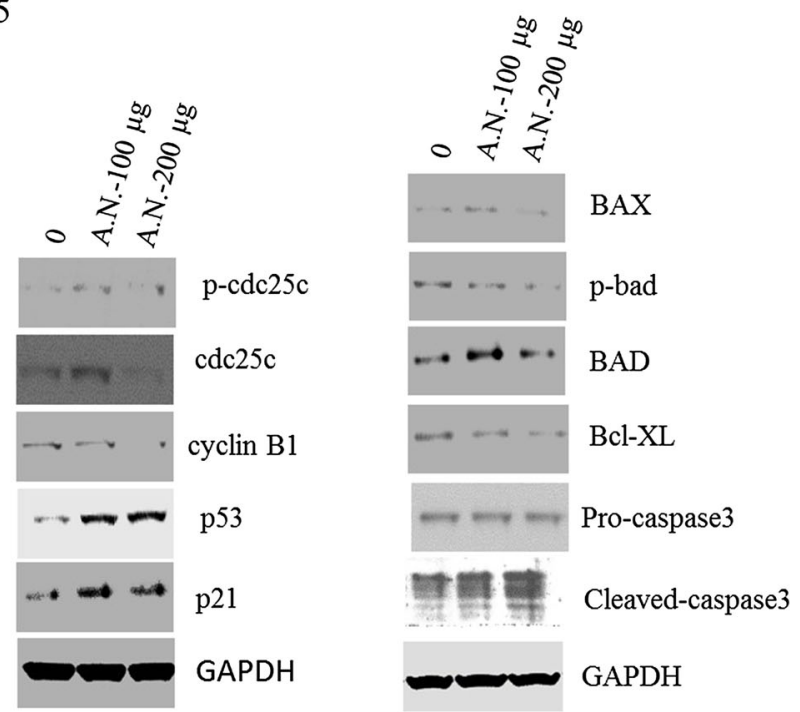

western blot analysis with p-cdc25c, cdc25c, cyclin B1, p53 and p21 antibodies. GAPDH used as an internal control. c Effect of $A$. nallamalayana (A.N) on protein levels of proapoptotic and antiapoptotic proteins. Cell lysates of A375 skin cancer cells treated with indicated concentrations of A. nallamalayana for $48 \mathrm{~h}$ and whole cell lysates were subjected to western blot analysis with BAX, p-BAD, $\mathrm{BAD}, \mathrm{Bcl}-\mathrm{XL}$, procaspase-3 and cleaved caspase-3 antibodies. GAPDH used as an internal control

A375 cells compared to controls. The results suggest that regulatory proteins are involved in AN leaf extract induced apoptosis of A375 cells.

Activation of pro-apoptotic proteins, such as BAD and BAX, results in induction of apoptotic cascade by forming pores in the mitochondrial membrane and subsequent increase in cytosolic concentration of cytochrome- $c$, which in turn activates effector caspases such as caspase-3. The whole cell lysates were subjected to western blotting to recognize the cleavage of caspase- 3 in A375 cells. As shown in the Fig. 5c, AN extract treatment significantly increased the levels of cleaved caspase-3 in a dose-dependent manner, suggests that AN leaf extract induces apoptosis in A375 cells.

\section{AN leaf extracts inhibits the nuclear translocation}

To further examine the mechanism of inhibition of cell proliferation following AN extract treatment, the activity of NF- $\mathrm{KB}$ signaling pathway which is known to play crucial roles in inflammation, cell survival and apoptosis of skin cancer cell lines were assessed. Briefly NF-kB nuclear translocation was induced with TNF $\alpha$ in B16F10 cells, followed by AN leaf extract treatment for $24 \mathrm{~h}$ and nuclear levels of p65 was measured using immunofluorescence. The nuclear translocation of p65 was increased following $\mathrm{TNF} \alpha$ stimulation in B16F10 cells, interestingly AN 
extract treated cells significantly reduced the TNF $\alpha$-induced nuclear p65 levels in B16F10 cells (Fig. 6) and p65 was mostly localized in cytosol.

\section{AN leaf extracts reduces reporter gene activation

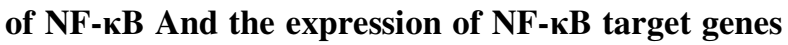

Once NF- $\mathrm{KB}$ is activated, it further translocates to nucleus and activates expression of its target genes. Study was extended to know the effect of AN extract treatment on $\mathrm{NF}-\kappa \mathrm{B}$ activation. B16F10 cells that were transiently transfected with pNF- $\kappa B-L u c-R e p o r t e r$ plasmid, and pRLTK (for normalization of transfection efficiency) plasmid, were treated with AN leaf extracts followed by TNF $\alpha$ stimulation. As shown in Fig. $7 \mathrm{a}, \mathrm{NF}-\kappa \mathrm{B}$ reporter gene activity is increased significantly following TNF- $\alpha$ stimulation compared to unstimulated $\mathrm{B} 16 \mathrm{~F} 10$ cells and this enhanced reporter activity is potentially inhibited by AN leaf extract. Results clearly suggest that AN extracts significantly inhibit NF- $\kappa B$ signaling pathway activation that leads to reduction in cell proliferation. NF- $\kappa B$ enhances the cell proliferation, survival and activates the inflammation by increasing the expression of IL- 1 beta, IL- 6 and cyclin D1 which are well known NF-kB-regulated genes. Gene expression levels of IL-1 beta, IL-6 and cyclin D1 were tested using qRT-PCR. As shown in Fig. 7b, the expression levels of IL-1 beta, IL-6 and cyclin D1 were decreased dose dependently after AN extract treatment in A375 cells. Results suggest that AN treatment regulates the expression of NF- $\kappa B$ target gene expression by inhibiting NF- $\kappa B$ activation.

\section{Discussion}

Cancer is one of the leading causes of death worldwide and the numbers of cancer cases are gradually increasing globally. There are different kinds of medicines available in the market to treat the several types of cancer but till date no drug is found to be safe and effective. One of the major impediments in the cancer chemotherapy is the toxicity of the established chemotherapeutic drugs. In recent years, the use of plants and plant derived products has proved to be effective and safe in the treatment and management of several types of cancers. Currently, most of the research work on cancer drugs is based on plants and plants-derived natural products. Since ancient time, plant products were used for health benefits by all cultures as well as source of medicines (Ignacimuthu et al. 2006; Elujoba et al. 2005; Tomlinson and Akerele 1998). Several natural products and their analogs have been identified as potent anti-cancer agents and the identification of anti-
DAPI
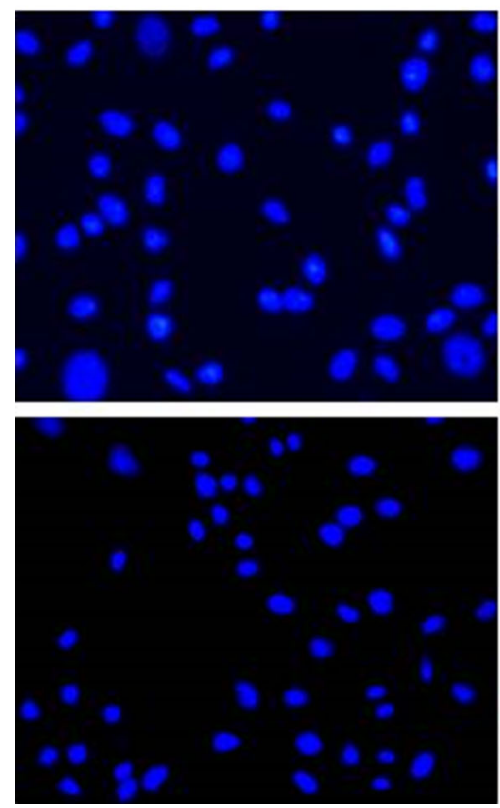

Fig. 6 Effect of A. nallamalayana (A.N) on TNF $\alpha$ induced nuclear translocation of p65. B16F10 cells were seeded on to coverslips in 24 well plates and pretreated with vehicle or A. nallamalayana (A.N) leaf extracts for $48 \mathrm{~h}$, followed by stimulation with $\mathrm{TNF} \alpha(10 \mathrm{ng} / \mathrm{ml})$ for $30 \mathrm{~min}$. Cells were then fixed in $4 \%$ paraformaldehyde and incubated with p65 primary antibody followed by FITC conjugated
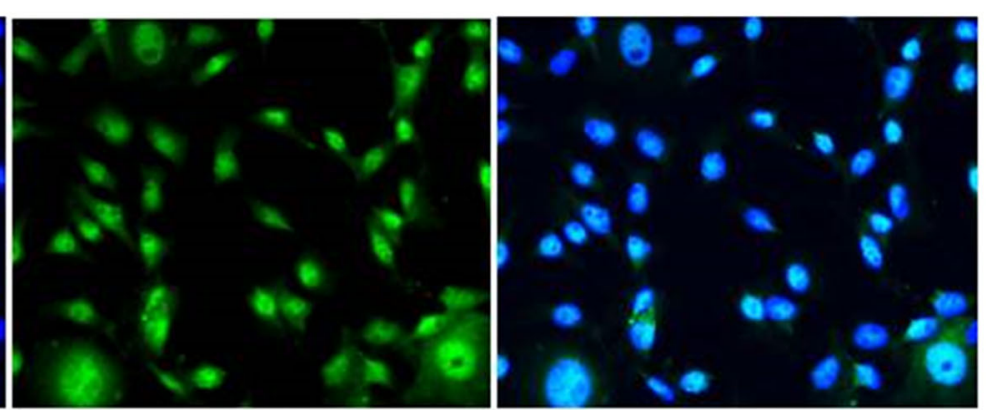

Control
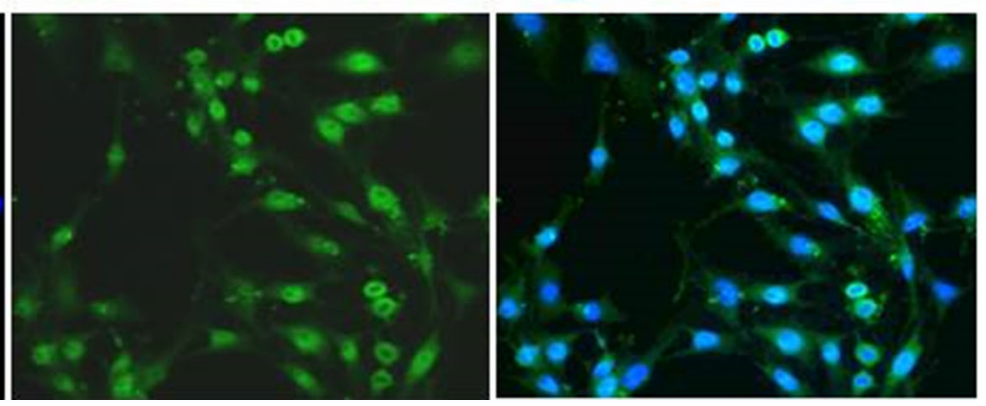

A. nallamalayana

secondary antibodies for $1 \mathrm{~h}$ at room temperature. Fluorescence was captured under fluorescence microscope. DAPI was used to visualize the nuclei. Upon stimulation with TNF $\alpha$, P65 was translocated to nucleus. A. nallamalayana (A.N) treatment resulted in the inhibition of nuclear translocation of p65 following TNF $\alpha$ stimulation and most of the p65 is localized in the cytosol 


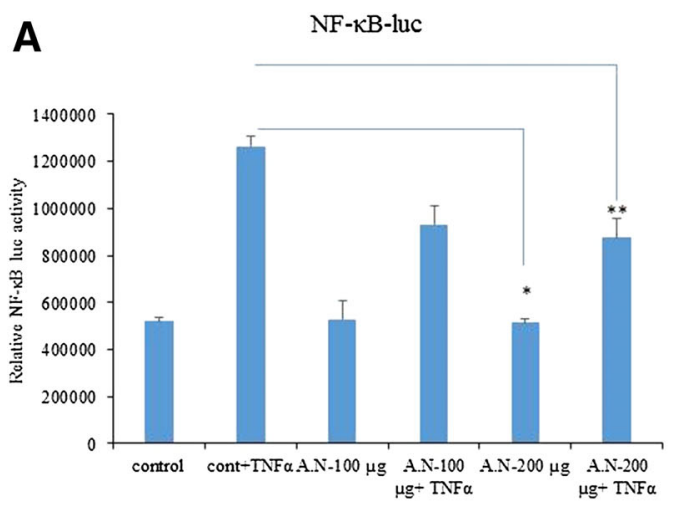

Fig. 7 Effect of A. nallamalayana (A.N) on TNF $\alpha$ induced NF-kB reporter gene activation and its target genes. A. B16F10 cells were seeded in 24-well plates and transiently transfected with pNF- $\kappa$ BLuc-Reporter and pRL-TK (for normalization of transfection efficiency) plasmids using fugene 6 transfection reagent as described in materials and methods. After $6 \mathrm{~h}$ cells were treated with indicated concentrations of $A$. nallamalayana (A.N) for $48 \mathrm{~h}$ followed by TNF $\alpha$ stimulation for $24 \mathrm{~h}$. Cells were lysed in passive lysis buffer and luciferase values were measured using dual luciferase assay system.

cancer property of various plants is being unraveled in significant manner. In the present study we have chosen a beautiful herb, endemic to few pockets of Nallamala hills in Indian peninsular, known for treating various ailments such as mouth ulcers and leukoderma in folklore medicine, persisting with antimicrobial and anti-psoriatic properties. Essentially, it is a rare plant with flourishing medicinal properties.

In the study, attempts were made to examine whether AN persists with any anti-cancerous properties such as anti-proliferative, anti-inflammatory and pro-apoptotic activities on A375 and B16F10 skin cancer cell lines. MTT cell viability assays and clonogenic assays revealed that AN leaf extracts have significant anti-proliferative effects on skin cancer cell lines. Further TUENL assays also demonstrated that AN induced the apoptosis of skin cancer cell lines. These results supports the notion that AN leaf extracts reduce the cell viability, and concomitantly activate the apoptosis.

Cell cycle checkpoints are important regulatory mechanisms that ensure the proper passage of cells through the cell cycle. The G2/M and G1/S checkpoints are critical in maintaining DNA integrity and essential in executing the proper cell cycle events. The G2/M checkpoint is one of the important check points that blocks the entry into mitosis when DNA is damaged (Taylor and Stark 2001). It was known that loss of regulation of these checkpoints resulted into transformation and progression of cancer cells. A protein kinase complex consisting of a catalytic subunit, Cdk1 (previously known as cdc2) and the cyclin B protein (Cdk1/cyclin B1 complex) regulates the central and rate-limiting function in the transition from $\mathrm{G} 2$ to $\mathrm{M}$ phase
The firefly luciferase activities were normalized against renilla luciferase activities. A. nallamalayana (A.N) reduced the NF-kBdependent reporter activity in a dose-dependent manner. b A375 cells were treated with vehicle $(0.1 \%$ DMSO) or indicated concentrations of A. nallamalayana (A.N) for $24 \mathrm{~h}$. RNA was isolated and subjected to RT-qPCR using the primers specific for IL- 1 beta, IL- 6 and cyclin D1. All data presented are the mean \pm SEM. $* p<0.05$, $* * p<0.01$, *** $p<0.001 t$ test

(Norbury 1992). In response to DNA damage, the cdc2/cyclin B1 complex causes a delay in cell cycle progression at G2/M phase to allow DNA repair before cells enter mitosis. This was achieved by phosphorylating cytoskeleton proteins such as lamins and histone H1 (Johnson and Walker 1999). Cdk1/cyclin B1 complex formation itself is not enough for cell cycle progression. However, the event of dephosphorylation of cdk1 at the Tyr-15 site through cdc25c phosphatase is required for the optimal activation of the cdk1/cyclin B1 complex (Sampath and Plunkett 2001). In the present study, AN treatment of A375 skin cancer cells resulted in inhibition of various cell cycle proteins. To elucidate the molecular mechanism, alterations in the levels of various cell cycle proteins were estimated and found that a decrease in levels of Cdk1, cyclin B1 and cdc25c following AN extract treatment, suggests the inhibitory activities of AN leaf extracts on G2/ $M$ phase of cell cycle arrest.

The transcriptional factor $\mathrm{p} 53$ functions as a guardian of the genome by modulating appropriate responses to stress as well as DNA damage. In addition, several studies showed the significant role of p53 in cell cycle checkpoint control. It has been showed that p53 blocks cell cycle at G2/M phase through direct inhibition of cdc2 kinase (Taylor and Stark 2001). It was also known that p53 regulate the G2/M phase transition through the induction of p21, a protein that normally inhibits cyclin B1-Cdc2 complexes in the cytoplasm (Bunz et al. 1998) or through the induction of apoptosis (Shaw et al. 1992). The present study revealed that AN leaf extract treatment resulted in stabilization of p53 protein expression. Further, it was found that several apoptotic genes including BAX, BAD 
were upregulated and survival genes such as Bcl-XL was down regulated in A375 skin cancer cell lines. Moreover, AN significantly increased the cleavage of Caspase-3. p21 is an inhibitor of cyclin/cyclin-dependent kinase complexes and its induction is mediated by both p53-dependent and p53-independent mechanisms and plays essential roles in both G1 and G2 cell cycle arrest in response to DNA damage and cell senescence (Roninson 2002). The study demonstrates that AN treatment significantly increased the expression of cdk inhibitor, p21 which contributed to the G2/M arrest and growth inhibition of A375 skin cancer cells.

Solar UV radiation-induced skin cancer or photocarcinogenesis is a complex process that involves a cascade of individual steps which includes apoptosis, proliferation, autophagy, DNA repair, checkpoint signaling, metabolism and inflammation. Several signaling pathways regulate the events. Of which NF- $\kappa \mathrm{B}$ signaling pathway plays key roles in inflammation, cellular proliferation, and induction of cancers (Kim and He 2014). NF- $\kappa \mathrm{B}$ is a family of dimeric transcription factors that play vital roles in diverse physiological processes and various human malignancies. NF$\kappa \mathrm{B}$ family includes RelA/p65, RelB, c-Rel, p50/p105 and p52/p100. In unstimulated cells, NF- $\kappa \mathrm{B} / \mathrm{Rel}$ dimers are bound to $\mathrm{I} \kappa \mathrm{B}$ and retained in cytoplasm. In response to stimulus such as TNF $\alpha$, LPS the I $\mathrm{B}$ proteins are phosphorylated by an activated $\mathrm{I} \kappa \mathrm{B}$ kinase (IKK) complex at positions 32 and 36 followed by polyubiquitination and degradation by $26 \mathrm{~S}$ proteasome releasing free $\mathrm{NF}-\kappa \mathrm{B}$ dimers. Then the p50/65 complex translocates to nucleus and binds to their target gene promoters and drives their transcription (Karin et al. 2002; Nishikori 2005). NF- $\kappa \mathrm{B}$ is activated by UVB radiation and contributes to UVB-induced skin carcinogenesis (Syed et al. 2012). Because inhibition of NF- $\mathrm{KB}$ activation has been linked with antitumor activities, it was hypothesized that AN mediates their effect at least partly through inhibition of $N F-\kappa B$ activation. In this study, the inhibitory effects of $\mathrm{AN}$ extracts on nuclear translocation of p65 were examined. Results showed that $\mathrm{TNF} \alpha$-induced nuclear translocation and $\mathrm{NF}-\kappa \mathrm{B}$-dependent reporter gene expression were inhibited following AN treatment. Moreover, AN extracts reduced the $\mathrm{NF}-\mathrm{kB}$ reporter gene activation and also reduced the NF-kB targeted genes expression including IL1 beta, IL-6 and cyclin D1.

In conclusion, methanolic leaf extracts of the endemic herb AN reduced the proliferation and induced apoptosis of skin cancer cell lines. Mechanistic studies revealed that AN targets the G2/M phase by altering the expression of proteins involved in $\mathrm{G} 2 / \mathrm{M}$ phase, by inducing expression of pro-apoptotic proteins and by inhibiting the NF-kB pathway activation. The findings might help in providing the rationale to initiating in vivo studies to examine the efficacy of AN as chemopreventive agent against skin cancer.

\section{Compliance with ethical standards}

Conflict of interest We declare that we have no conflict of interest.

Open Access This article is distributed under the terms of the Creative Commons Attribution 4.0 International License (http:// creativecommons.org/licenses/by/4.0/), which permits unrestricted use, distribution, and reproduction in any medium, provided you give appropriate credit to the original author(s) and the source, provide a link to the Creative Commons license, and indicate if changes were made.

\section{References}

Abhishek N, Tewari SK, Lehri Alok (2010) Biological activities of Kalmegh (Andrographis Paniculata Nees) and its active principles-a review. IJNPR 1(2):125-135

Agbonlahor O, Joyce EF, Osayemwenre E, Vincent I, Abiodun F, Peter L (2014) Harnessing the medicinal properties of Andrographis paniculata for diseases and beyond: a review of its phytochemistry and pharmacology. Asian Pac J Trop Dis 4(3):213-222

Ajay KR, Sridevi K, Vijay KN, Nanduri S, Rajagopal S (2004) Anticancer and immunostimulatory compounds from Androphis paniculata. J Ethnopharmacol 92:291-295

Bunz F, Dutriaux A, Lengauer C, Waldman T, Zhou S, Brown JP, Sedivy JM, Kinzler KW, Vogelstein B (1998) Requirement for p53 and p21 to sustain G2 arrest after DNA damage. Science 282(5393):1497-1501

Churiyah OB, Elrade R (2015) Antiviral and immunostimulant activities of Andrographis paniculata. HAYATI J Biosci 2(22):67-72

Dhiman A, Goyal J, Sharma K, Nanda A, Dhiman S (2012) A review of medicinal prospectives of Andrographis Paniculata Nees. JPSI 1(1):1-4

Ekor M (2014) The growing use of herbal medicines: issues relating to adverse reactions and challenges in monitoring safety. Front Pharmacol 4(177):1-10

Elujoba AA, Odeleye OM, Ogunyemi CM (2005) Traditional medicine development for medical and dental primary health care delivery system in Africa. Afr J Tradit Compliment Altern Med 2(1):46-61

Geethangili M, Rao YK, Fang SH, Tzeng YM (2008) Cytotoxic constituents from Andrographis paniculata induce cell cycle arrest in jurkat cells. Phytother Res 22(10):1336-1341

Ignacimuthu S, Ayyanar M, Sivaraman SK (2006) Ethnobotanical investigations among tribes in Madurai district of Tamil Nadu (India). J Ethnobiol Ethnomed 2(25):1-7

Johnson DG, Walker CL (1999) Cyclins and cell cycle checkpoints. Annu Rev Parmacol Toxicol 39:295-312

Karin M, Cao Y, Greten FR, Li ZW (2002) NF-kappa B in cancer: from innocent bystander to major culprit. Nat Rev Cancer 2:301-310

Kim Y, He YY (2014) Ultraviolet radiation-induced non-melanoma skin cancer: regulation of DNA damage repair and inflammation. Genes Dis 1(2): 188-198

Lin HH, Shi MD, Tseng HC, Chen JH (2014) Andrographolide sensitizes the cytotoxicity of human colorectal carcinoma cells toward cisplatin via enhancing apoptosis pathways in vitro and in vivo. Toxicol Sci 139(1):108-120

Luo X, Luo W, Lin C, Zhang L, Li Y (2014) Andrographolide inhibits proliferation of human lung cancer cells and the related mechanisms. Int J Clin Exp Med 7(11):4220-4225 
Mzid M, Khan TA, Mohammad F (2012) Medicinal plants of rural India: a review of use by Indian folks. Indo Global J Pharm Sci 2(3):286-304

Nishikori M (2005) Classical and alternative NF- $\kappa$ B activation pathways and their roles in lymphoid malignancies. J Clin Exp Hematopathol 45:15-24

Norbury C, Nurse P (1992) Animal cell cycles and their control. Annu Rev Biochem 61:441-470

Padma Y, Venkata Raju RR (2013) Phytochemical screening and evaluation of antimicrobial activity of Andrographis nallamalayana Ellis, a rare and endangered species. Am J PharmTech Res 3(1):957-962

Pandey MM, Subha R, Rawat AKS (2013) Indian traditional Ayurvedic system of medicine and nutritional supplementation. A review-Evid based compliment. Alternat Med 7:1-12

Parlapally S, Cherukupalli N, Bhumireddy SR, Sripadi P, Anisetti R, Giri CC, Khareedu VR, Vudem DR (2015) Profiling and antipsoriatic activity of methanolic extract of Andrographis nallamalayana J.L.Ellis. Nat Prod Res 8:1-6

Prakash OM, Kumar A, Kumar P (2013) Anticancer potential of plants and natural products: a review. AJPS 1(6):104-115

Rajagopal S, Kumar RA, Deevi DS, Satyanarayana C, Rajagopalan R (2003) Andrographolide, a potential cancer therapeutic agent isolated from Andrographis paniculata. J Exp Ther Oncol 3(3):147-158

Rates SMK (2001) Plants as source of drugs. Toxicon 39:603-613
Roninson I (2002) Oncogenic functions of tumor suppressor p21Waf1/Cip1/Sdi1: association with cell senescence and tumor-promoting activities of stromal fibroblasts. Cancer Lett 179:1-14

Sagadevan P, Suresh SN, Ranjithkumar R, Rathishkumar S, Sathish S, Chandarshekar B (2015) Traditional use of Andrographis paniculata: review and perspectives. Int $\mathrm{J}$ Biosci Nanosci 2(5):123-131

Sampath D, Plunkett W (2001) Design of new anticancer therapies targeting cell cycle checkpoint pathways. Curr Opin Oncol 13(6):484-490

Shaw P, Bovey R, Tardy S, Sahli R, Sordat B, Costa J (1992) Induction of apoptosis by wild-type $\mathrm{p} 53$ in a human colon tumorderived cell line. Proc Natl Acad Sci 89:4495-4499

Syed DN, Afaq F, Mukhtar H (2012) Differential activation of signaling pathways by UVA and UVB radiation in normal human epidermal keratinocytes. Photochem Photobiol 88(5):1184-1190

Taylor WR, Stark GR (2001) Regulation of the G2/M transition by p53. Oncogene 20:1803-1815

Tomlinson TR, Akerele O (1998) Medicinal plants: their role in health and biodiversity. University of Pennsylvania Press, Philadelphia

Venkata Ratnam K, Venkata Raju RR (2005) Folk medicine used for common women ailments by Adivasis in the Eastern Ghats of Andhra Pradesh. Indian J Trad Knowl 4(3):267-270 